\title{
Laboreal
}

Volume 11 №2 | 2015

Varia

\section{Da compreensão coletiva da atividade real à conceção participativa da organização: por uma intervenção ergonómica capacitante}

De la comprensión colectiva de la actividad real al diseño participativo de la organización: promover la intervención ergonómica "capacitante" De la compréhension collective de l'activité réelle à la conception participative de l'organisation: plaidoyer pour une intervention ergonomique capacitante From the collective understanding of the actual activity to the participatory organization design: encourage an "empowering" ergonomic intervention

\section{Anne Raspaud}

\section{OpenEdition}

\section{Journals}

\section{Edição electrónica}

URL: http://journals.openedition.org/laboreal/3766

DOI: 10.4000/laboreal.3766

ISSN: 1646-5237

\section{Editora}

Universidade do Porto

\section{Refêrencia eletrónica}

Anne Raspaud, « Da compreensão coletiva da atividade real à conceção participativa da organização: por uma intervenção ergonómica capacitante », Laboreal [Online], Volume 11 №2 | 2015, posto online no dia 01 dezembro 2015, consultado o 24 setembro 2020. URL : http://journals.openedition.org/ laboreal/3766 ; DOI : https://doi.org/10.4000/laboreal.3766

Este documento foi criado de forma automática no dia 24 setembro 2020.

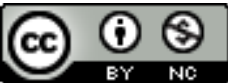

Laboreal está licenciado com uma Licença Creative Commons - Atribuição-NãoComercial 4.0 Internacional. 


\section{Da compreensão coletiva da atividade real à conceção participativa da organização: por uma intervenção ergonómica capacitante}

De la comprensión colectiva de la actividad real al diseño participativo de la organización: promover la intervención ergonómica "capacitante"

De la compréhension collective de l'activité réelle à la conception participative de l'organisation: plaidoyer pour une intervention ergonomique capacitante From the collective understanding of the actual activity to the participatory organization design: encourage an "empowering" ergonomic intervention

\section{Anne Raspaud}

\section{REFERÊNCIA}

Raspaud, A. (2014). De la compréhension collective de l'activité réelle à la conception participative de l'organisation : plaidoyer pour une intervention ergonomique capacitante. Thèse de doctorat en ergonomie, Conservatoire National des Arts et Métiers, Paris.

\section{NOTA DO EDITOR}

http://dx.doi.org/10.15667/laborealxi0215arpt

Manuscrito recebido em: outubro/2015

Aceite após peritagem: novembro/2015 
1 Esta tese aplica e desenvolve o paradigma da ergonomia construtiva à conceção da organização. Apoiando-se numa intervenção de (re)conceção de um processo de prestação de cuidados inovador (a cirurgia ambulatória), define e operacionaliza uma metodologia de intervenção capacitante que coloca o desenvolvimento como meio e finalidade da ação.

\section{A cirurgia ambulatória: um conceito de prestação de cuidados inovador que responde às necessidades de racionalização da prestação de cuidados}

2 Esta investigação-intervenção, conduzida num Centro Hospitalar Universitário francês, insere-se num contexto nacional de reforma hospitalar que tem impacto nas condições de trabalho de todos os profissionais de saúde e no atendimento geral dos pacientes. Novos modelos de organização dos cuidados de saúde são implementados com o desenvolvimento do atendimento substitutivo da hospitalização a tempo inteiro. Estas evoluções respondem a dois desafios principais: responder melhor às diversas necessidades dos pacientes e otimizar o recurso aos cuidados hospitalares, pensando o hospital como um local de prestação de cuidados sem necessidade de internamento.

3 A cirurgia ambulatória constitui uma alavanca para uma transformação profunda dos modelos de organização da prestação dos cuidados de saúde. 0 processo de prestação de cuidados é transversal às diferentes especialidades médicas e aos diferentes serviços, e revela uma forma particular de atividade coletiva: a atividade coletiva conjunta (Lorino, 2009). A fim de se poder realizar a prestação de cuidados, várias atividades são levadas a cabo (simultaneamente ou não) nas relações de interdependência complexas e de coordenações reforçadas, no seio de entidades distintas (serviços, equipas, polos) que mobilizam operadores de diversos perfis profissionais (cirurgiões, anestesistas, enfermeiros,...). O trabalho é assim condicionado pela articulação entre os diferentes atores, com múltiplas lógicas, e que têm que colaborar para atender os pacientes.

\section{Problemática e objetivos da tese}

4 A investigação-intervenção centra-se na conceção desta organização. Foi pensada não só como geradora de soluções visando o melhor compromisso entre os objetivos de bem-estar e desempenho (Falzon, \& Mas, 2007), mas também como uma ação que suporta o desenvolvimento constante e conjunto das pessoas, dos coletivos de trabalho e das organizações. Baseia-se na abordagem das capabilidades iniciada por Sen (2000) e, mais especificamente, sobre a abordagem das capabilidades coletivas (Evans, 2002). Definem-se não pela simples justaposição ou agregação das capabilidades individuais, mas advêm sim da emergência de uma possibilidade nova e coletiva de agir e de criar. Permitem aos operadores envolvidos numa atividade coletiva serem capazes de agir em torno de um objetivo comum. Três elementos, fundadores e em interação, foram identificados como necessários para o desenvolvimento das capabilidades coletivas: a atividade coletiva dos operadores (o motor), definido pela interação enriquecedora do trabalho coletivo e do coletivo de trabalho (Caroly, 2010), as estruturas organizacionais adequadas (o suporte) e o capital social entre estes atores (o lubrificante). 
5 Nesta abordagem, a atividade coletiva constrói e alimenta o desenvolvimento dos sujeitos e dos coletivos e constitui o motor da aprendizagem, da transformação e da performance, recurso para a emergência de novas liberdades para os indivíduos. 0 indivíduo e o coletivo vão então ter a oportunidade concreta de alcançar o que legitimamente valorizam, realizar um trabalho bem feito (Arnoud, 2013). Isto requer um ambiente favorável para que as capabilidades coletivas possam ser exercidas e transformadas em realizações de valor, que Sen descreve como as condições necessárias para que um direito formal se torne uma capacidade real (Falzon \& Mollo, 2009): um ambiente capacitante (Falzon, 2005).

6 Colocar o desenvolvimento no centro do processo da intervenção ergonómica é simultaneamente construir a ação para encorajar o desenvolvimento e organizar uma situação de desenvolvimento (Falzon, 2013). Para a ergonomia, a questão é a de saber como instruir, construir e equipar a intervenção para que ela permita:

- Implementar uma dinâmica que permita e incentive a confrontação das representações e o seu debate: trata-se de pensar a intervenção como um processo pedagógico de transformação, a oportunidade de uma dinâmica de desenvolvimento e de aprendizagem.

- Construir uma situação futura que permita aos indivíduos, aos coletivos e às próprias organizações de se transformar e de aprender; por outras palavras, intervir é procurar conceber uma organização capacitante (Arnoud, 2013).

\section{Metodologia de investigação}

Duas etapas estruturaram a investigação-intervenção.

Uma primeira fase de diagnóstico consistiu em analisar o funcionamento do processo de cirurgia ambulatória nas três unidades de cirurgia ambulatória do centro hospitalar universitário (CHU), a fim de compreender se a organização constitui um travão ou um motor para o desenvolvimento da atividade coletiva conjunta. Dois tipos de métodos foram utilizados:

- Observações papel e lápis. Após 120 horas de observações abertas, foram realizadas 60 horas de observações sistemáticas, focadas no percurso dos pacientes (desde o seu acolhimento na unidade de cirurgia ambulatória até à sua saída) com vista a analisar as atividades individuais (gestão simultânea de pacientes...) e as interações entre os diferentes atores.

- 80 entrevistas semiestruturadas com 30 pacientes e 50 profissionais de saúde foram realizadas, com vista a recolher as suas representações sobre a cirurgia ambulatória (nível de conhecimento, expectativas, nível de aceitabilidade, potenciais impedimentos). As 80 horas de entrevistas foram objeto de uma análise de conteúdo por temas.

o diagnóstico evidenciou a transformação profunda dos padrões profissionais dos prestadores de cuidados gerada pela cirurgia ambulatória e a sua dificuldade em construir uma organização que promove a atividade coletiva conjunta. A atividade de cirurgia ambulatória surge segmentada e o paciente circula de um segmento para o outro sem verdadeiras cooperações construídas ou coordenações organizadas entre as equipas. Existem coletivos de trabalho por especialidade, mas não um "coletivo de trabalho ambulatório", vetor de coesão e coerência.

10 Uma segunda fase consistiu na construção de uma metodologia de conceção participativa de uma organização da cirurgia ambulatória que suporta o desenvolvimento de uma atividade coletiva conjunta e das capabilidades coletivas. 
Centrou-se na especialidade cirúrgica de orto-traumatologia. Foi criado um grupo de trabalho, constituído por 25 operadores do processo de cirurgia ambulatória pertencentes a equipas multiprofissionais; foi animada pelo ergónomo investigador e por uma profissional de saúde especializada na análise das práticas profissionais.

11 Cada reunião do grupo de trabalho foi gravada, transcrita e foi objeto de uma análise de conteúdo. Cinco etapas estruturaram esta fase da conceção:

- Etapa 1: Constituir uma reserva de situações que permitam ao ergónomo apoiar e estimular o debate. Para tal, foi realizado um segundo momento de 98 horas de observações no serviço em questão.

- Etapas 2 e 3: Construir uma representação comum da atividade real a partir da simulação coletiva de um caso concreto proposto pelas animadoras; para tal, uma metodologia inspirada na abordagem de processo (Lorino, 2003) foi utilizada para se encontrar a linearidade e o encadeamento das lógicas de ação que concorrem para satisfazer as exigências da prestação de cuidados, que são mais do que uma sucessão de etapas independentes e compartimentadas entre as equipas multiprofissionais. 0 grupo de trabalho materializou o processo ambulatório de forma cronológica num friso de papel que responde às seguintes questões: "Quem, $\mathrm{O}$ Quê, Onde, Quando, Como". Cada participante que intervém na construção do processo verbalizou conjuntamente a sua atividade simulada.

- Etapa 4: Decidir os objetivos a atingir coletivamente. As animadoras apresentaram ao grupo de trabalho uma síntese das trocas previamente analisadas por temática e dos esboços das soluções propostas na simulação.

- Etapa 5: Formalizar a atividade futura e confrontar as soluções. Foram constituídos três subgrupos de 5 pessoas, cada um com um representante de cada função, para suportar a atividade coletiva conjunta. Cada subgrupo propôs as soluções escritas num paperbord e submeteu-as oralmente ao grupo de trabalho argumentando as escolhas feitas, seguindo uma lista de questões precisas fornecidas pelas animadoras.

\section{Principais resultados da investigação: os determinantes de uma intervenção capacitante}

12 A análise dos dados recolhidos (conteúdos das trocas, papel do ergónomo) permitiu evidenciar uma série de princípios chave para que uma intervenção seja capacitante, isto é, neste caso, que permita o desenvolvimento conjunto das pessoas e do coletivo e a performance da organização:

\subsection{Tornar mobilizável a disponibilidade dos recursos efetivos e potenciais dos indivíduos}

13 As discussões sobre o trabalho, através da criação de espaços de debate e de apoios às memórias da atividade evocadas pelo ergónomo (questões de clarificação e situações de ações dinamicamente evocadas pelo ergónomo) implicaram uma tomada de consciência, caraterizada por dois fatores (Mollo, 2004):

- A análise do processo é feita à distância da tarefa efetiva. Os participantes estão, então, concentrados nos seus conhecimentos e competências, postos em ação no decurso da atividade. 
- Ao tornarem-se analistas da sua própria atividade e da dos outros, os participantes explicitaram o que faziam, como e porque o faziam. Não se trata só de dizerem o que sabiam, mas de descobrirem um saber implícito individual e coletivo e de outras formas de "fazer".

14 Através das trocas e das discussões dos constrangimentos, das dificuldades, dos critérios de qualidade, etc., o trabalho é reificado, tornado exterior ao trabalhador (Falzon, 2005). Os operadores têm assim a oportunidade real de reinterrogar coletivamente as regras.

\subsection{Implantar a atividade coletiva conjunta para construir um coletivo de trabalho}

15 A intervenção através da construção, das trocas e dos debates coletivos sobre o processo de cirurgia ambulatória "real" permitiu desenvolver uma forma de atividade coletiva conjunta que não existia no início. 0 ergónomo levou os protagonistas da prestação de cuidados ambulatórios a lançar as bases essenciais de um trabalho coletivo e de construir os contornos de um coletivo de trabalho de cirurgia ambulatória. Isto permitiu: um conhecimento partilhado do processo sem a globalidade e a emergência de referências comuns, um conhecimento de trabalho do outro e uma cultura coletiva, um reconhecimento das competências de cada um e da sua necessária complementaridade, uma confiança mútua nas informações trocadas e nas ações efetuadas.

\subsection{Permitir que os recursos do coletivo de trabalho se transformem e se tornem "capabilidades coletivas"}

O investigador-ergónomo, pela metodologia implementada, deu ao grupo de trabalho tornado "coletivo de trabalho", a possibilidade de ter uma ação sobre a sua própria situação de trabalho e de assim aumentar o seu poder de agir, ou seja, construir "um espaço de liberdade, autorizado pela organização, em que ele pode construir e investir" (Coutarel, 2004, p. 168, tradução livre). Isto permitiu-lhe encontrar novas vias, novas formas de fazer o trabalho. Os operadores, pela mobilização dos seus recursos individuais em capabilidades coletivas, fazem a escolha partilhada de "fazer melhor juntos", de se coordenar e de definir um objetivo coletivo comum.

\section{Permitir a conversão das capabilidades coletivas em funcionamentos efetivos}

O trabalho de reorganização é tornado possível porque a organização propôs um ambiente favorável à contribuição positiva dos prestadores de cuidados no processo de conceção coletiva do cuidar. Os operadores beneficiam de uma liberdade que lhes permite realmente aplicar os recursos de que dispõem e elaborar as regras formais que favorecem o desenvolvimento das regras efetivas aceitáveis para a atividade coletiva e individual, nomeadamente a coordenação da prestação de cuidados e a colaboração profissional. 


\section{Conclusão}

18 A metodologia desenvolvida, fundada nos princípios da ergonomia construtiva, permitiu propor um modelo que participa no desenvolvimento dos indivíduos (graças à implementação do saber-fazer, de conhecimentos, de competências), dos coletivos (graças à criação de condições organizacionais que permitam a construção e o desenvolvimento das diferentes formas de coletivo de trabalho) e das organizações (graças à integração na organização de processos reflexivos, abertos às capacidades de inovação dos próprios operadores) (Falzon, 2013).

19 A generalização a outras situações de conceção parece possível devido à transversalidade das questões levantadas e do método utilizado. A intervenção centrouse na organização de um sistema complexo (pelas caraterísticas técnicas do processo, o número e a diversidade de atores). Esta especificidade não parece ser um obstáculo à reutilização do modelo em situações menos complexas. Somente o estudo do pedido e a análise da organização a (re)conceber permitirão justificar se faz sentido desenvolver esta metodologia à luz do balanço resultados esperado / projeto a implementar (nível de análise da atividade necessária, número de atores solicitados em simultâneo, formas de difusão dos resultados para outros profissionais, a construção social da intervenção....) .

\section{BIBLIOGRAFIA}

Arnoud, J. (2013). Conception organisationnelle : pour des interventions capacitantes. Thèse de doctorat en ergonomie, Conservation National des Arts et Métiers, Paris.

Caroly, S. (2010). Activité collective et réélaboration des règles: Des enjeux pour la santé au travail. Habilitation à Diriger des Recherches, Université Bordeaux 2, France.

Coutarel, F. (2004). La prévention des troubles musculo-squelettiques en conception : quelles marges de manœuvre pour le déploiement de l'activité ? Thèse de doctorat en ergonomie, Université Victor Segalen. Bordeaux 2, France.

Evans, P. (2002). Collective Capabilites, Culture and Amartya Sen's Development as Freedom. Studies in Comparative International Development, 37 (1), 54-60.

Falzon, P. (2005). Ergonomie, conception et développement. Conférence introductive présentée au 40e congrès de la Société d'Ergonomie de Langue Française [SELF], Saint-Denis.

Falzon, P. (2013). Pour une ergonomie constructive. In P. Falzon (Ed.), Ergonomie constructive (pp. 1-15). Paris : PUF.

Falzon, P., \& Mas, L. (2007). Les objectifs de l'ergonomie et les objectifs des ergonomes. In M. Zouinar, G. Valléry, \& M. C. Le Port (Eds.), Ergonomie des produits et des services, Actes du 42e Congrès de la SELF. Toulouse : Octarès.

Falzon, P., \& Mollo, V. (2009). Pour une ergonomie constructive : Les conditions d'un travail capacitant. Laboreal, 5(1), 61-69. 
Lorino P. (2003). Méthodes et pratiques de la performance. Le pilotage par les processus et les compétences. Paris : Editions d'Organisation.

Lorino, P. (2009). Concevoir l'activité collective conjointe : l'enquête dialogique. Etude de cas sur la sécurité dans l'industrie du bâtiment. Activités, 6(1), 87-110.

Mollo, V. (2004). Usage des ressources, adaptation des savoirs et gestion de l'autonomie dans la décision thérapeutique. Thèse de doctorat en ergonomie, Conservatoire National des Arts et Métiers, Paris.

Sen, A. K. (2000). Un nouveau modèle économique. Développement, justice, liberté. Paris : éditions Odile Jacob.

\section{AUTOR}

\section{ANNE RASPAUD}

Pôle Stratégie médico-scientifique, Hôtel Dieu - CHU de Toulouse, 2 rue Viguerie TSA 80035, 31059 Toulouse, France

raspaud.a@chu-toulouse.fr 